\title{
The potential impact of weight status on visual attention to physical activity related cues
}

\author{
K.J. Doolan ${ }^{1}$, G. Breslin ${ }^{2}$, D. Hanna ${ }^{3}$ and A.M. Gallagher ${ }^{1}$ \\ ${ }^{1}$ Northern Ireland Centre for Food and Health, University of Ulster, Coleraine BT52 1SA, UK, ${ }^{2}$ Ulster Sports \\ Academy, University of Ulster, Jordanstown BT37 OQB, UK and ${ }^{3}$ School of Psychology, Queen's University Belfast, \\ Belfast, BT7 INN, UK
}

\section{K.J. Doolan awarded NS Irish Section Best Overall Student Poster Communication prize}

Physical activity is a key determining factor of energy expenditure and plays an integral role in both energy balance and weight control $^{(1)}$. The promotion of physical activity is included in many government policies and public health agency agendas however there remains a need to better understand how the general public process and engage in physical activityinformation ${ }^{(2)}$. Previous research has indicated that the visual environment may affect our behaviours and choices ${ }^{(3)}$ and more recently it has been suggested that physical activity information may be more effective if it targeted automatic visual attention systems ${ }^{(2)}$.

To date, a limited number of studies have investigated a potential link between higher self-reported levels of physical activity and greater visual attention to physical activity related cues $^{(4,5)}$ however it has remains to be seen whether body weight status may also have a role. As individuals classified as being overweight or obese may be less likely to meet current physical activity recommendations than their normal weight counterparts ${ }^{(6)}$, the aim of this study was to investigate for the first time the potential impact of body weight status on the attentional processing of physical activity related visual cues.

Twelve normal weight (mean BMI 23.2, SD $1 \cdot 6 \mathrm{~kg} / \mathrm{m}^{2}$ ) and twelve overweight/obese (mean BMI $29 \cdot 6, \mathrm{SD} 3 \cdot 3 \mathrm{~kg} / \mathrm{m}^{2}$ ) females aged 18-65 years participated in an eye tracking paradigm in which eye movements to physical activity and non-physical activity(control) images were recorded. Using a mixed-design ANOVA, results demonstrated a main effect of image type with all participants attending to physical activity images (mean 473.4, SD $162 \cdot 6 \mathrm{~ms}$ ) for a longer duration than control images (mean 333.7, SD $116 \cdot 1 \mathrm{~ms}$ ), $F(1,22)$ $=11.52, p=0.003$. There was also an image $\mathrm{x}$ weight group effect observed with overweight/obese females attending to physical activity images for a shorter duration (mean 439.4, SD 66.6) than their normal weight counterparts (mean 482.7, SD 67.8), $F(1,22)=4 \cdot 71, p=0.042$ (see Figure). A positive correlation was observed between self-reported hours per day spent in moderate to vigorous activities and gaze duration (ms) to physical activity related images, $\mathrm{r}=0.51, p=0.014$ for all female participants regardless of weight status.

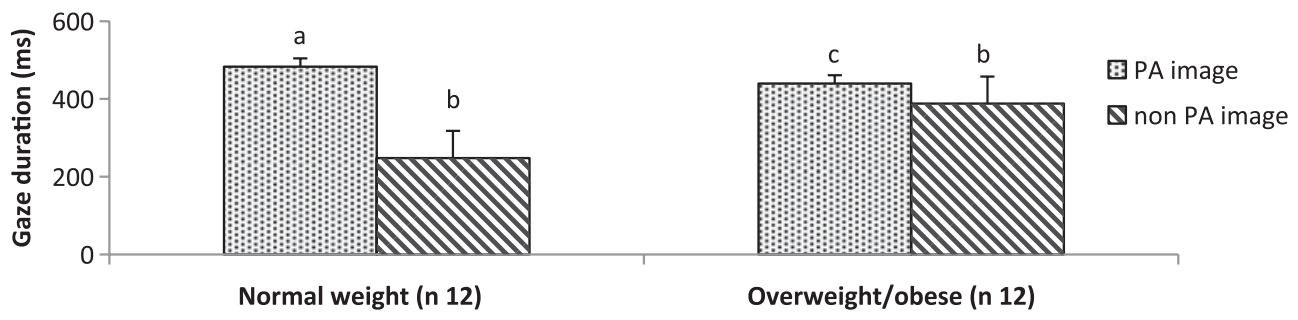

Abbreviations: PA, physical activity.Mixed design ANOVA: weight group as between- subject factor; image type (PA vs. control) (ms) as within-subject factor. Different letters represent statistically significant differences

Results from this study confirm previous findings that individuals with higher levels of self-reported physical activity appear to be more attentive to physical activity related images. Findings also demonstrate for the first time, potential weight group differences in attentional processing of visual physical activity related stimuli with overweight/obese females being less attentive to physical activity images compared to normal weight females.

This indicates the importance of avoiding a 'one size fits all' approach in designing and assessing the effectiveness of public health messages targeted at different population groups such as those who are normal weight as compared to those who are overweight or obese.

1. Public Health England Obesity Lifestyle and Behaviours Factsheet Available at: http://www.noo.org.uk/NOO_about_obesity/lifestyle\#d6901 (Accessed on 11/03/14)

2. Berry TR, Spence JC \& Stolp SM (2011) Res Q Exerc Sport 82, 302-309.

3. Robinson TE \& Berridge KC (1993) Annu Rev Psychol 53, 25-53.

4. Calitri R et al. (2009) Psychology and Health 24, 1105-1123.

5. Berry TR (2006) J. Sport Exerc. Psychol 28, 4-17.

6. Information Centre report: Statistics on obesity, physical activity and diet: England (2011) Available at: http://www.hscic.gov.uk/catalogue/ PUB00210/obes-phys-acti-diet-eng-2011-rep.pdf (Accessed on 11/03/14) 